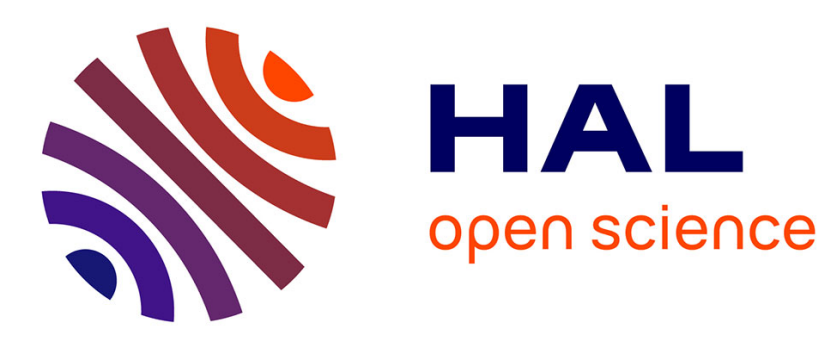

\title{
The "Sym'Previous" software, a tool to support decisions to the foodstuff safety
}

Benoit Leporq, Jeanne Marie J. M. Membré, Catherine Dervin, Patrice Buche, J.P. Guyonnet

\section{- To cite this version:}

Benoit Leporq, Jeanne Marie J. M. Membré, Catherine Dervin, Patrice Buche, J.P. Guyonnet. The "Sym'Previous" software, a tool to support decisions to the foodstuff safety. International Journal of Food Microbiology, 2005, 100 (1-3), pp.231-237. 10.1016/j.ijfoodmicro.2004.10.006 . hal-02683138

\section{HAL Id: hal-02683138 \\ https://hal.inrae.fr/hal-02683138}

Submitted on 1 Jun 2020

HAL is a multi-disciplinary open access archive for the deposit and dissemination of scientific research documents, whether they are published or not. The documents may come from teaching and research institutions in France or abroad, or from public or private research centers.
L'archive ouverte pluridisciplinaire HAL, est destinée au dépôt et à la diffusion de documents scientifiques de niveau recherche, publiés ou non, émanant des établissements d'enseignement et de recherche français ou étrangers, des laboratoires publics ou privés. 

foodstuff safety.

B. Leporq ${ }^{1}$, J.-M. Membré ${ }^{1}$, C. Dervin ${ }^{2 *}$, P. Buche ${ }^{2}$ and J.P. Guyonnet ${ }^{3}$

4

5

61 Institut National de Recherche Agronomique, 369 rue Jules Guesde BP 39, F-59651

$7 \quad$ Villeneuve d'Ascq cédex, France

8 2. UMR BIA INA P-G/ INRA, Paris 16, rue Claude Bernard 75231 Paris, cédex 5 , France

9 3. Arilait Recherches, 42 rue de Châteaudun, 75009 Paris, France

10

11 Keywords: Sym'Previus, Predictive microbiology, Database, Food safety

\footnotetext{
${ }^{*}$ Corresponding author. Tel. : +3314408 16 76; fax : +3314408 1666

E-mail address : dervin@inapg.inra.fr
} 


\section{1}

2 Describing the Sym'Previus project, the software and its deliverable facilities is the aim of

3 this present paper. This software concerns all the partners of the food industry who are

4 involved in the management of food safety and allows food borne pathogen behaviour in food

5 to be predicted, as function of the environment (nature of the food, manufacturing process,

6 conditions of conservation). This analysis of microbial behaviour has been possible thanks to

7 the progress made in predictive microbiology since the 80's. Sym'Previus offers to food

8 industry professionals and their partners the possibility of applying this progress, by giving

9 access to a database, to simulation systems and expertise.

\section{Introduction}

11 The objective of the first release of the Sym'Previus software is to be able to answer queries concerning the food safety and particularly the behaviour of bacteria on a food matrix in case of contamination (Table 1).

14 Over the past few years, several attempts have been made to launch tools similar to Sym'Previus. The first one was Food MicroModel, a software package developed by MAFF from United Kingdom, and marketed by Leatherhead Food Research Association. The second one, named Pathogen Modelling Program (PMP), has been developed in the USA by the USDA, and is now downloadable from the Internet

19 (http://www.arserrc.gov/mfs/pathogen.htm).

Research in predictive microbiology has been pursued throughout a FLAIR research project funded by EU and carried out in 1990-93 (Peck et al. 1994). Research teams from 12

European countries participated in this project, whose co-ordinator was Dr T. Roberts, from IFR. Afterwards the project was followed by a COST project (914) aiming to organise 
1 on the validation of models on real food products. Another European project, named

2 PREMIUM, directed by Prof. Dr. Jan Van Impe from the Katholieke Universiteit Leuven,

3 was implemented and funded in the $4^{\text {th }}$ Framework. Its main objectives were to elaborate a

4 unified modelling system, and to validate it on real food products as well.

5 The origins of the Sym'Previus project can be situated in accordance with a number of

6 factors:

- several French scientific teams had participated in the European projects named above, and found them promising; especially a leader of the food industry who developed an application based on cardinal models (Rosso, 1995), and used it in real conditions, in plants manufacturing fresh dairy products.

- the French government was very interested in the opportunity of implementing an expertise in the domain of pathogens, in order to improve the general security level of foodstuffs; moreover, a further application of such a tool in Quantitative Risk Assessment was considered as well.

- The French food industry were interested also in participating in the building of a common software, to share their expertise in food safety and their data (challengetests, models, bacterial strains...).

All these conditions lead to the building of a network, including industry, research, technical centres, the Ministry of Agriculture and the Ministry of Research, funded by governmental grants and financial contribution of the participants (Leporq et al., 2003).

\section{The software facilities}

To collect information on bacterial behaviour in food, the users can obtain data from three different units : i) a database, ii) a simulation system and iii) a data analysis tool (expertise), as shown in Figure 1. 


\subsection{A relational database of food microbiology}

2 The database was built in order to integrate food, bacteria and environmental characteristics

3 (formulation, $\mathrm{pH}, \mathrm{a}_{\mathrm{w}}$, culture condition, manufacturing process, condition of conservation ...)

4 on microbial behaviour (growth, inactivation, survival...) concerning pathogenic germs able

5 to contaminate food, and also epidemiological data (prevalence or level of contamination in

6 food). The database contains data stemming from various sources, like scientific publications

7 (more than 700 selected for their interest in food microbiology), industrial partners and R\&D

8 laboratories. The use of these data can be divided into different groups. Firstly, growth rates

9 can be used directly by comparing the correspondence between the growth rate predicted by

10 the simulation software and to the data extracted from the database. Secondly, growth kinetics

11 could be used, either to estimate primary models parameters (such as growth rate), or to be

confronted to kinetics simulations. Moreover, these data bring information on microbial

behaviour in food under a specific combination of environmental factors, and then complete

information when the corresponding model is not yet available (for example, the impact of the

15 packaging, or the incidence of thermal stress on lag time).

This database is enquired through the web-based browser called MIEL (Figure 2), a

multicriterion system, specifically developed for this database and performing fuzzy querying

thanks to an additional knowledge discussed in Buche et Loiseau (1999) and Buche et al.

(2002). MIEL crosses the user demand about food, micro-organism and environmental

20 factors. However, this basic query is not always satisfying, the nature of the data and their

21 multiple providers render the database incomplete by nature. It is not realistic to think that this

22 database contains experimental data for all food products, all pathogen germs, under all

23 conditions. Therefore MIEL is a querying system which retrieves the nearest data compared

24 to the selection criteria specified by the user. 


\subsection{Predictive models in order to simulate growth kinetics}

2 Today, a large variety of primary and secondary models exists to describe the behaviour of

3 micro-organisms in food, submitted to the influence of environmental factors. Sym'Previus

4 does not reiterate the equations, advantages, disadvantages and connections between the

5 models. A large literature is available on theses subjects. Nevertheless, the most known and

6 used models are presented through the free web site (http://www.symprevius.org).

7 Concerning the scientific knowledge used in this software, the model called "delay and break"

8 developed by Rosso et al., 1995, has been selected as primary model, and cardinal models

9 including interpretable parameters $\left(\mathrm{T}_{\min }, \mathrm{T}_{\mathrm{opt}}, \mathrm{T}_{\max }, \mathrm{pH}_{\min } \ldots\right)$ have been chosen as secondary

10 models (Rosso et al., 1995) to describe the effect of the temperature, $\mathrm{pH}$ and $\mathrm{a}_{\mathrm{w}}$ effect on

11 growth rate. About lag time, more scientific results are needed before introducing them in

12 simulations.

\subsubsection{Microbial growth in food, in case of contamination}

In order to simulate the behaviour of pathogenic bacteria in foodstuff, the modelling approach is based on the gamma concept (Eq.1) (Zwietering et al., 1992). Each unit, $\tau(\mathrm{T}), \rho(\mathrm{pH})$ and $\alpha\left(a_{w}\right)$ was quantified by a cardinal secondary model (Rosso et al., 1995). The effects of each factor were combined and an extra parameter corresponding to the effect of the foodstuff on the growth rate, called $\mu_{\mathrm{opt}}$, was added.

$$
\mu_{\max }=\mu_{o p t} \cdot \tau(T) \cdot \rho(p H) \cdot \alpha\left(a_{w}\right)
$$

This approach was successfully validated in foods (Pinon et al. 2004 ; Membré et al. 2004).

\subsubsection{Software facilities}

The starting assumption of this tool of simulation is that the user does not know which particular strain could contaminate his/her product. In this way the specific parameters (cardinal values) of this strain are ignored. It is probably more interesting to provide a "mean" response of the species completed by an interval confidence (Huet et al., 1996) than to 
1 describe the behaviour of a specific strain unknown by the user. To illustrate the global

2 behaviour of the five pathogenic species studied during the Sym'Previus program, a specific

3 group was in charge of selecting among a large collection of strains (more than 1000) the

4 more representative and of determining their cardinal values (Membré et al., 2002, Membré et

5 al., 2003).

6 Concerning the facilities developed in this tool, the simulation of the behaviour of growth of 7 pathogenic bacteria on different families of foodstuffs is provided (Figure 3). The user has to 8 i) select a food matrix and the associated micro organism (already tested among them), ii)

9 check if the parameters of $\mathrm{pH}$ and water activity of the food matrix proposed by default correspond to their product (theses values extracted from the experiments done in 11 Sym'Previus could be adjusted to the user product, in a defined range), finally iii) set the level 12 of the temperature factor. Furthermore, the result of this simulation is reported on a graph and available in a table to be exported to a spreadsheet as well. Moreover, the user could confront

14 results given by modelling to data obtained independently from his own laboratory or stored in a database by adding theses data to the graph. The comparison on the same graph of the influence of two temperature levels or two food matrix, is also possible.

17 Few bonus were included for users who would like to go further. Firstly, a table which summarises the three environmental factors and the food influences in order to appreciate the most preponderant factor modifying the growth rate (Eq. 1). Secondly, a graph presenting the data which have permitted to determine the model parameters (i.e. cardinal values and the

21 interval confidence around the predicted values) is plotted.

\subsection{Expertise in food microbiology}

23 The major interest of Sym'Previus is not only to provide a database and mathematical models 24 but to combine information and to supply an analysis done by a group of experts 25 (microbiologists, statisticians) in order to summarise the knowledge. Figures 4 and 5 illustrate 
1 what is done with a request such as "which is the behaviour of Escherichia coli $\mathrm{O} 157: \mathrm{H} 7$ in

2 beef meat in a range of temperatures from refrigerated to room values ?". In the first time the

3 database is scanned about the association beef meat / Escherichia coli O157:H7 under the

4 influence of the temperature effect through the MIEL. Raw kinetics were extracted at

5 different levels (Figure 4). The first interest is to bring an accurate idea of the bacterial

6 behaviour on a product including variability due to different sources of data (different authors

7 and laboratories). Thus, from each kinetic a growth rate was estimated, plotted versus the temperature and compared to these obtained in liquid medium (Figure 5). A difference of

9 growth rates is observed, between data obtained in the food matrix and the data established in

10 liquid medium. To fit the model to the beef meat data, the food dependent parameter, $\mu_{\mathrm{opt}}$, is 11 adjusted (Eq. 1). Hence, the specific growth rate values of Escherichia coli on beef meat are 12 available in the software, without carrying out any new experiment.

13 In conclusion, this kind of expertise combines all the tools of Sym'Previus, and allows to 14 improve the knowledge on an association of food and micro organism by combining different sources of information and statistical treatment. Thus, this group of experts will be able to provide information to users who have difficulties using the tools, or who observe a

17 difference between their data and those provided by the software. Therefore, the most important advantage is that Sym'Previus is not only a database and a group of mathematical models, but overall a network of expertise, gathering laboratories, technical centres and companies, all of them being well aware of the difficulties and the traps

21 existing in the use of predictive microbiology. The objective is to provide a complete service, 22 including consultation of the database, simulation of growth, a guide for interpretation, and the opportunity to contact experts. 


\section{The Future of Sym'Previus}

2 A system like Sym'Previus necessitates a permanent updating and improvement of the service

3 offered to users every time it is possible. It will be necessary to add data about new germs and

4 continue to enrich the data on the pathogens already included in the database.

5 New research projects will also bring new data (some of them being already in progress) and create the possibility to improve the accuracy of simulations, for example a better estimation of lag phase, particularly on Listeria monocytogenes. In the future, some other research projects will have to be set up in order to take a better account of the diversity of food matrices and add factors to the models like organic acids, preservatives, or effects of different types of stress on micro organisms.

It would be probably very useful to implement links with other databases like ComBase so that we could share experience and knowledge with the other's European experts and in this way improve each other's performances in the field of food microbiology.

Since the beginning of 2004, the head laboratory of the Sym'Previus project has been moved from INRA (Villeneuve d'Ascq, France) to Adria (Quimper, France).

\section{Acknowledgements}

This project was part of the French national predictive microbiology program, Sym'Previus. It was supported by French Departments of Research and Agriculture.

\section{References}

Buche, P., Loiseau S, 1999. Using Contextual Fuzzy Views to Query Imprecise Data. Lecture Notes in Computer Science 1677. Conference Proceedings DEXA'99 460-472.[Database and EXpert system Application, Florence (Italy), August 99].

Buche, P., Dervin C., Brouillaud-Delattre, A., Gnanou-Besse, N., 2002. Combining fuzzy querying of imprecise data and predictive microbiology using category-based reasoning 
1 for prediction of the possible microbial spoilage in foods: application to Listeria 2 monocytogenes. International Journal of Food Microbiology 73, 171-185.

3 Huet, S., Bouvier, A., Gruet M.A., Jolivet E., 1996. Statistical tools for non linear regression.

Leporq, B., Membré, J-M., Zwietering, M., Dervin, C., Buche, P., Guyonnet J.P., 2003. The "Sym'Previus" software, a tool to support decisions to the foodstuff safety. In : J.F.M. Van Impe, A.H. Geeraerd, I. Leguérinel and P.Mafart (Eds), Predictive modelling in food - Conference Proceedings, 55-57, Société française de Microbiologie, 347pp. (ISBN 905682-400-7) [4 $4^{\text {th }}$ International Conference, Quimper (France), June 15-19,2003].

Membré, J.-M., Leporq, B., Vialette, M., Mettler, E., Perrier, L., Zwietering, M.H., 2002. Experimental protocols and strain variability of cardinal values $\left(\mathrm{pH}\right.$ and $\mathrm{a}_{\mathrm{w}}$ ) of bacteria using Bioscreen C: microbial and statistical aspects. In: L. Alexon, E.S. Tronrud and K.J. Merok (Eds), Microbial adaptation to changing environments - Conference Proceedings, 143-146, Matforsk Norwegian food research institute, 405pp. (ISBN NR:82-90394-88-8) [18th symposium of the International Committee on Food Microbiology and Hygiene, Lillehammer (Norway), August 18-23, 2002]

Membré, J.-M., Leporq, B., Vialette, M., Mettler, E., Perrier, L., Thuault, D., Zwietering, M.H., 2003. Temperature effect on bacterial growth rate : quantitative microbiology approach including cardinal values and variability estimates, to perform growth simulations on/in food. In: J.F.M. Van Impe, A.H. Geeraerd, I. Leguérinel and P. Mafart (Eds.), Predictive modelling in foods - Conference Proceedings. Katholieke Universiteit Leuven / BioTeC, Belgium.

Membré, J.-M., Kubaczka, M., Dubois, J., and Chèné, C. 2004. Temperature effect on Listeria monocytogenes growth in the event of contamination of cooked pork products. Journal of Food Protection, 67, 463-469. 
1 Peck, M.W., Roberts, T.A., Sutherland, J.P., Walker, S.J.,1994. Modelling the growth,

2 survival and death of microorganisms in foods: the UK Food Micromodel approach.

3 International Journal of Food Microbiology 23, 265-275.

4 Pinon, A., Zwietering, M. H., Perrier, L., Membré, J.-M., Leporq, B., Mettler, E., Thuault, D.,

5 Coroller, L., Stahl, V., \& Vialette, M. 2004. Development and Validation of Experimental

6 Protocols for Use of Cardinal Models for Prediction of Microrganism Growth in Food

$7 \quad$ Products. Applied and Environmental Microbiology 70, 1081-1087.

8 Rosso L., 1995. Modélisation et Microbiologie Prévisionnelle : élaboration d'un nouvel outil

9 pour l'agro-alimentaire, Thèse de doctorat, présentée devant l'Université Claude Bernard -

10 Lyon (France).

11 Rosso, L., Lobry, J.R., Bajard, S., Flandrois J.P., 1995. Convenient Model To Describe the 12 Combined Effects of Temperature and $\mathrm{pH}$ on Microbial Growth. Applied and 13 Environmental Microbiology 61 (2), 610-616.

14 Zwietering, M.H., Wijtzes, T., De Wit, J.C., Van'T Riet, K., 1992. A decision support system for prediction of the microbial spoilage in foods. Journal. of Food Protection 55 (12), 973979. 
Table 1 The software deliveries.

\begin{tabular}{|lll|}
\hline User & Aim & Query \\
\hline $\begin{array}{l}\text { Industrial } \\
\text { Companies }\end{array}$ & Challenge test & $\begin{array}{l}\text { Which information can be deducted from this experiment? } \\
\text { Which germs are concerned for my product? } \\
\text { Which product families behave in the same way? } \\
\text { Which impact of pH, sugar, organic acids or thermal } \\
\text { treatment on growth or survival of related pathogens ? }\end{array}$ \\
\hline Distributor & $\begin{array}{l}\text { Comparison of shelf life } \\
\text { conditions }\end{array}$ & $\begin{array}{l}\text { Growth occurring for real thermal profile with regard to } \\
\text { standard temperature }\end{array}$ \\
\hline $\begin{array}{l}\text { Governmental } \\
\text { Organisations }\end{array}$ & $\begin{array}{l}\text { Hazard incidence on a given } \\
\text { product }\end{array}$ & $\begin{array}{l}\text { Simulation of behaviour according to contamination, product } \\
\text { characteristics and shelf life conditions }\end{array}$ \\
\hline
\end{tabular}




\section{Figures}

Figure 1: description of the Sym'Previus units.

Figure 2: view of the web-browser: MIEL.

Figure 3: view of the simulation tool.

Figure 4: kinetics of Escherichia coli O157:H7 on ground beef meat, at various temperature levels, extracted from the database. The raw data refereed to $\mathrm{x}$-names, $\mathrm{x}=$ temperature level, names $=$ first author of the paper and year of the publication, or industrial Sym'Previus partner source.

Figure 5: example of exploitation of data by the model. The open squares correspond to growth rate values obtained on liquid medium as function of the temperature level, and circles to growth rates determined on ground beef meat. The thin continuous line represents the fitting on the mean value completed by the interval confidence in dotted lines (Huet et al.,1996). The bold line is the "final" fitting corresponding to the growth on the food product. 


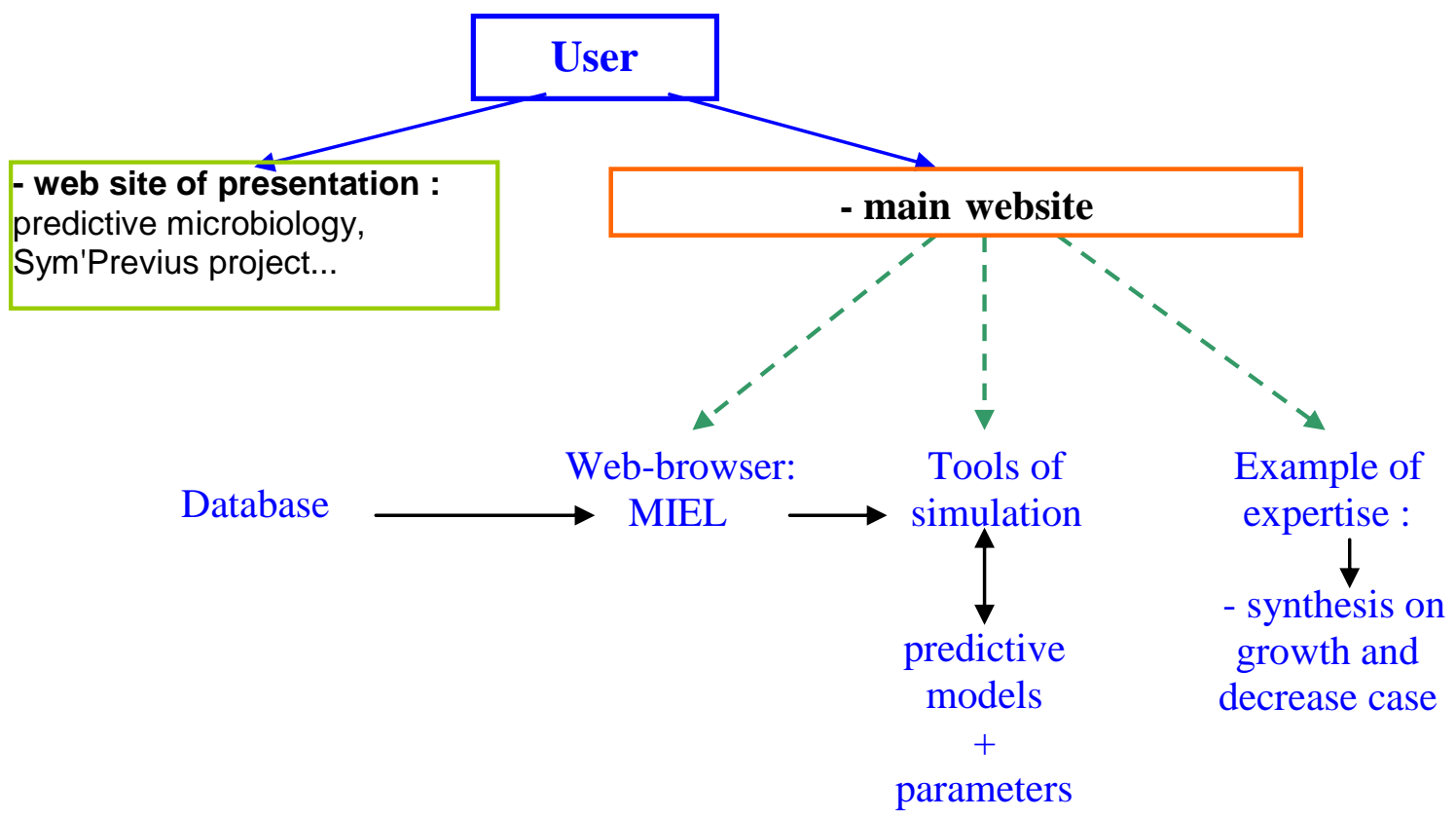




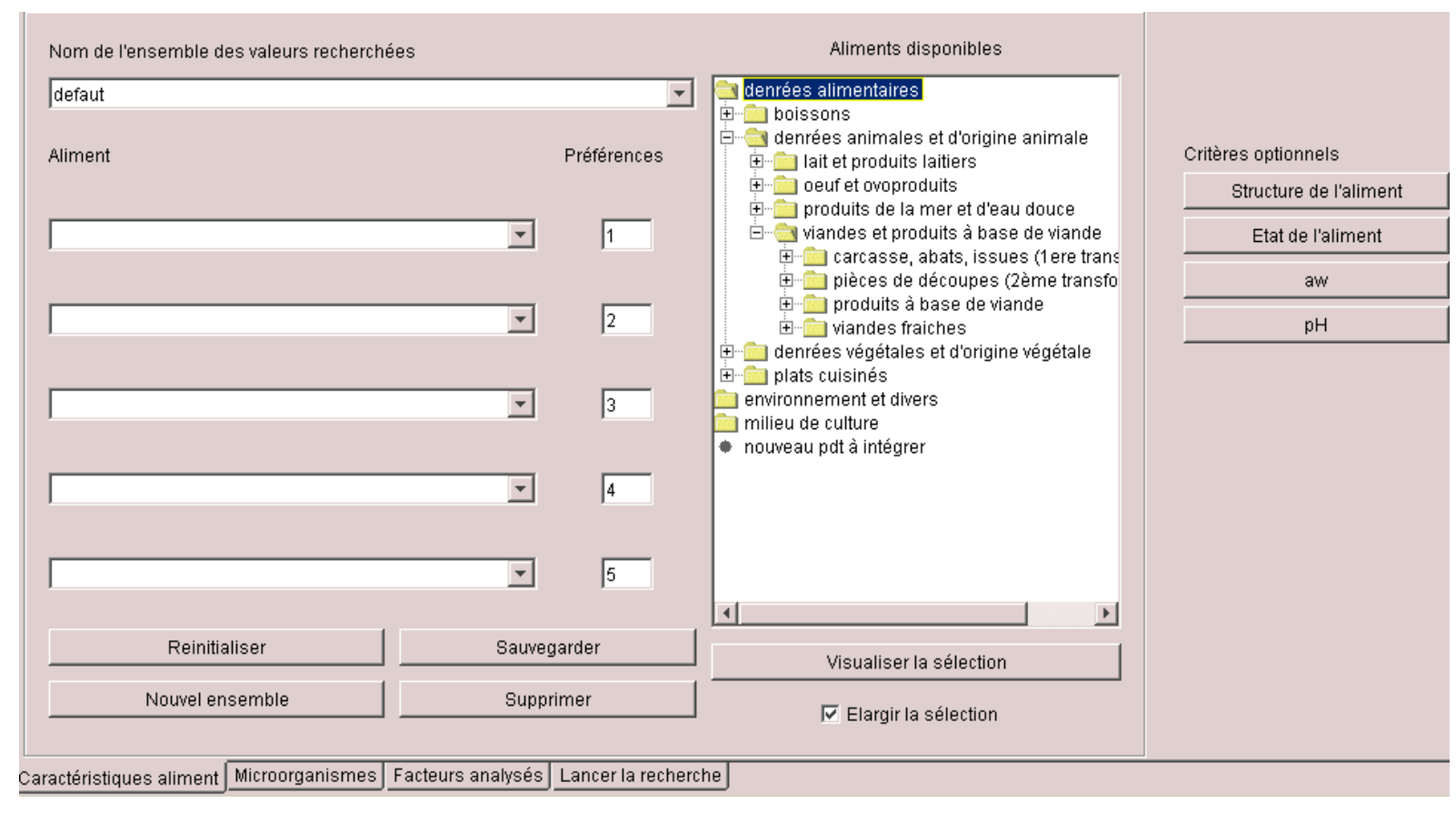




\section{le module dé simulation}

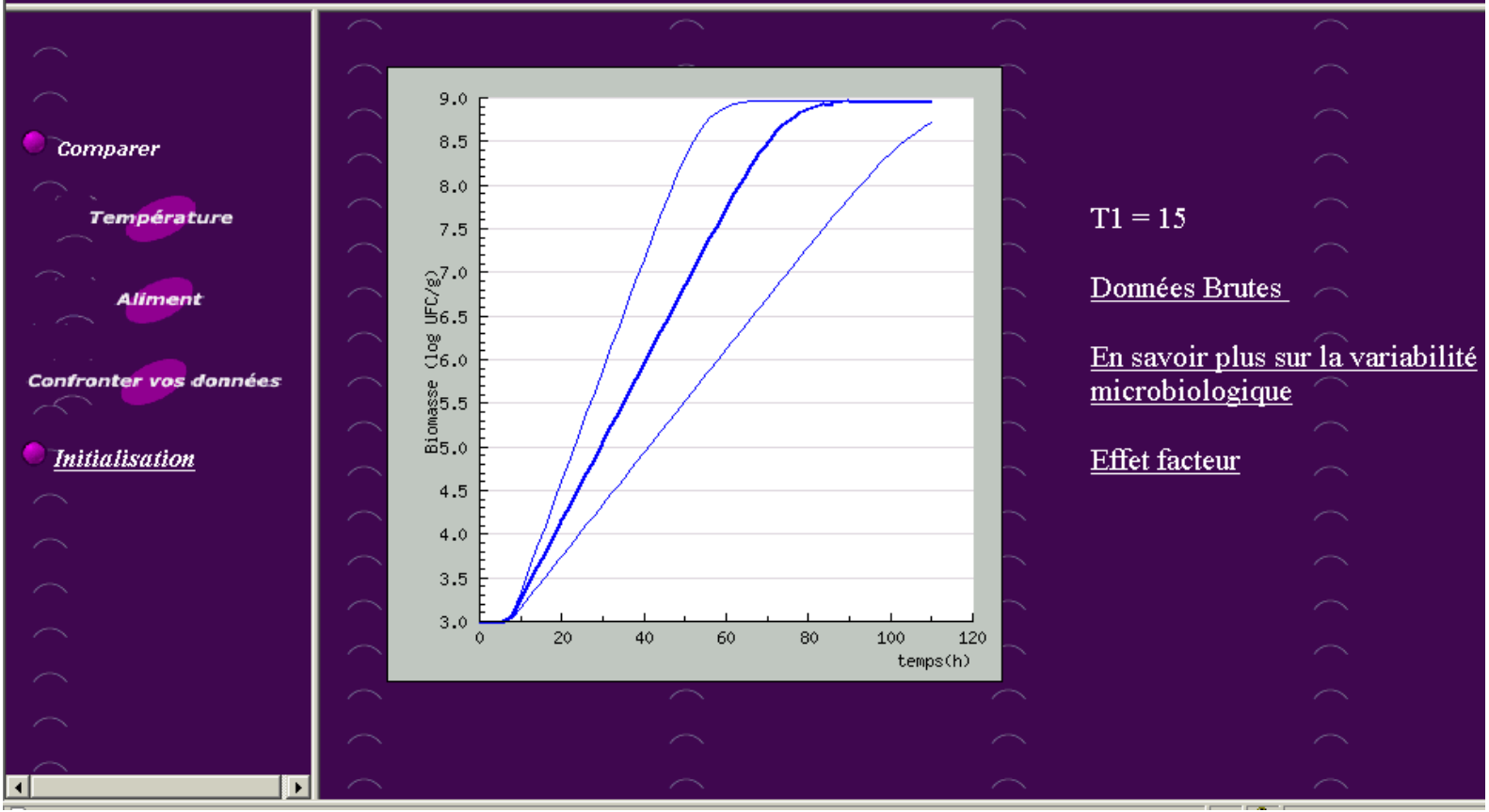




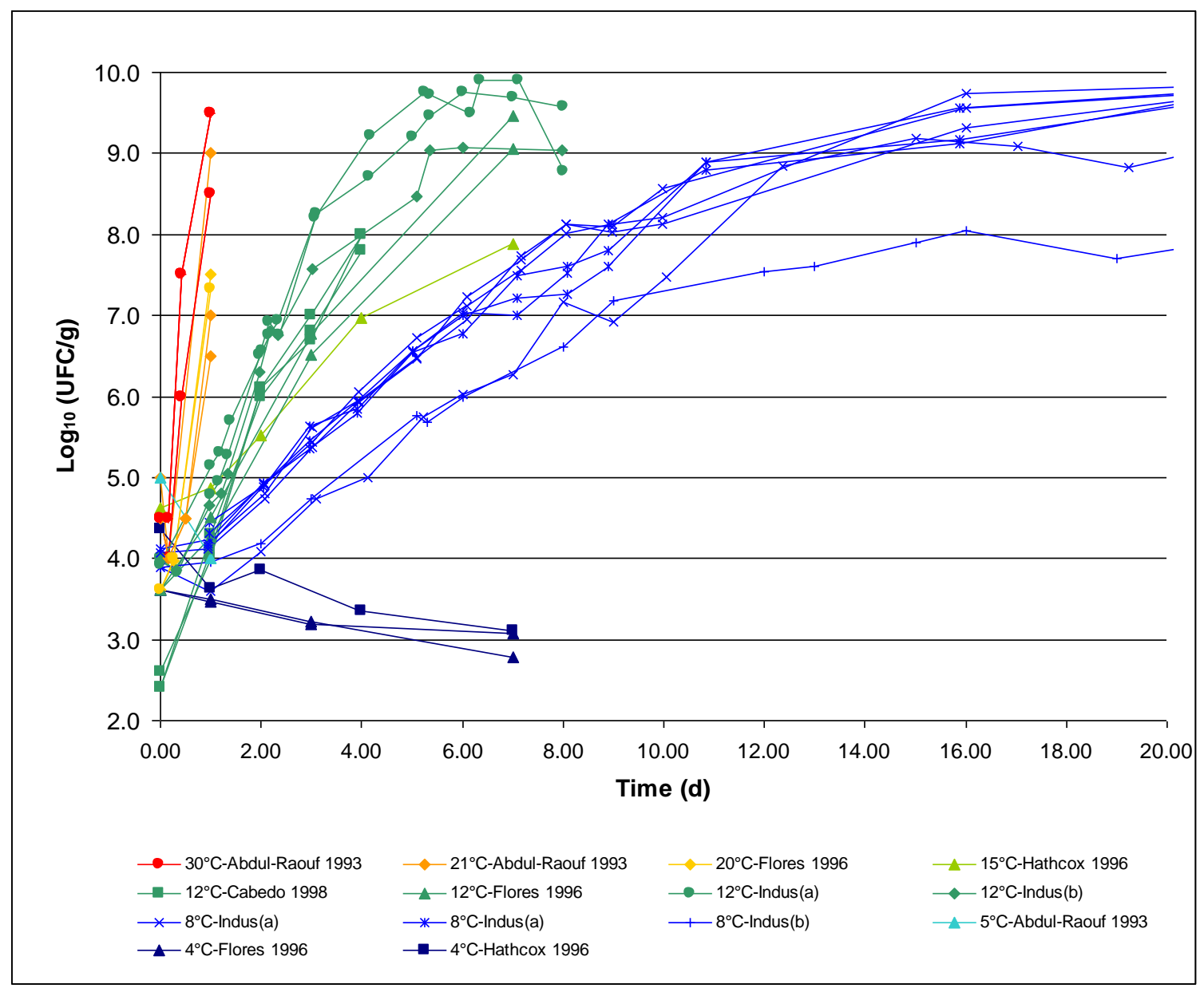




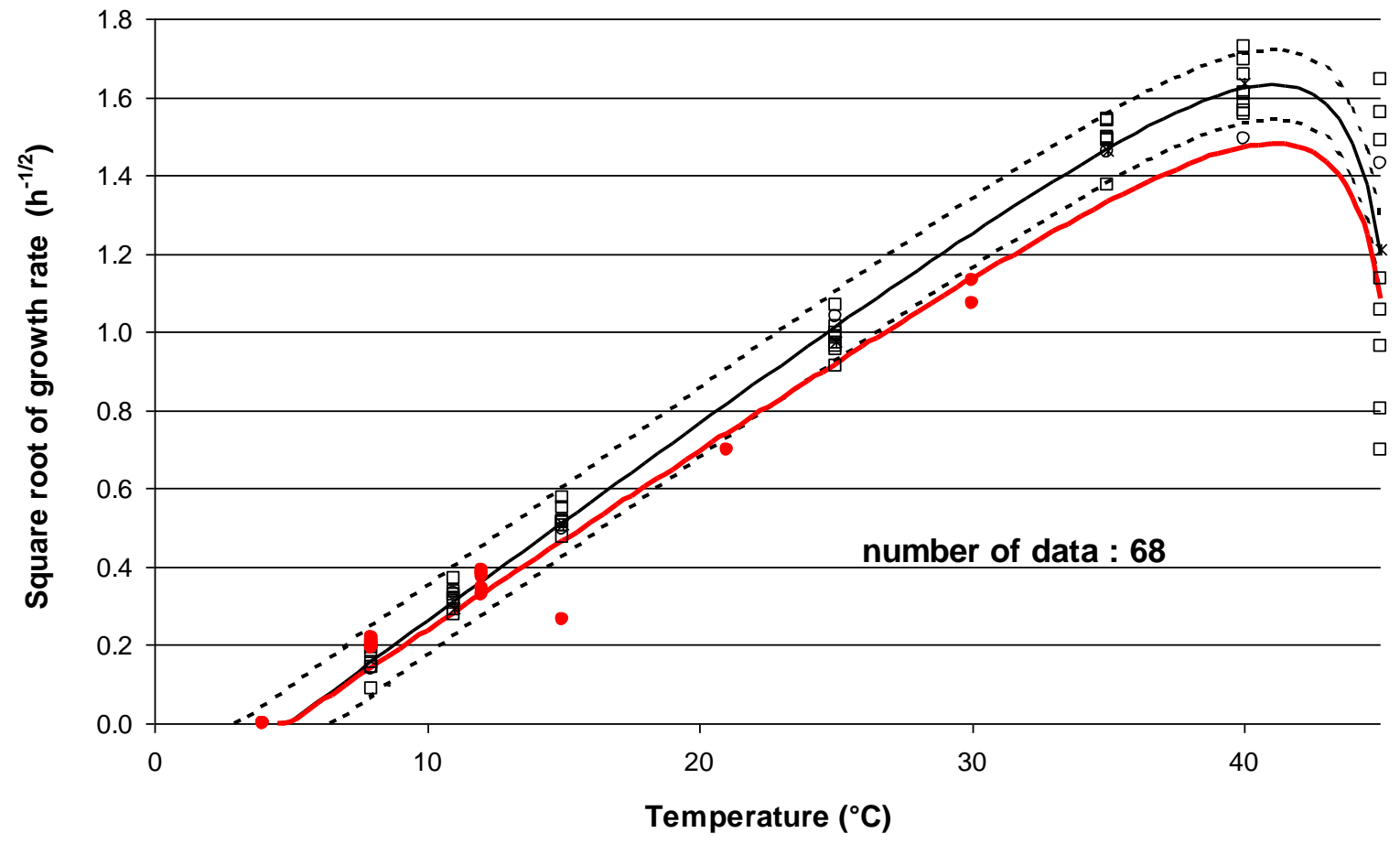

